\title{
Utility of a thin bronchoscope in facilitating bronchial thermoplasty
}

This article was published in the following Dove Press journal: Journal of Asthma and Allergy

\author{
David Langton ${ }^{1,2}$ \\ Nicole Gaffney' \\ Wei Chin Wang ${ }^{2}$ \\ Frank Thien ${ }^{2,3}$ \\ Virginia Plummer ${ }^{1,2}$ \\ 'Department of Thoracic Medicine, \\ Frankston Hospital, Peninsula \\ Health, Frankston, Melbourne, VIC, \\ Australia; ${ }^{2}$ Faculty of Medicine, \\ Nursing and Health Sciences, Monash \\ University, Melbourne, VIC, Australia; \\ ${ }^{3}$ Department of Respiratory Medicine, \\ Box Hill Hospital, Eastern Health, \\ Melbourne, VIC, Australia
}

Background: A significant correlation has been previously demonstrated between the quantum of radiofrequency treatment delivered at bronchial thermoplasty and the degree of improvement in an asthmatic patient's symptoms. The standard bronchoscope used for bronchial thermoplasty has an outer diameter of $4.8 \mathrm{~mm}$ at the distal tip. Thinner bronchoscopes are now available with the same internal channel size $(2.0 \mathrm{~mm})$. This study assesses whether using a thinner bronchoscope facilitates bronchial thermoplasty by increasing the radiofrequency activations delivered. Patients and methods: This was a sequential study in a single center, conducted in 27 patients with very severe asthma. The first 12 patients (Group 1) underwent bronchial thermoplasty using the standard bronchoscope, Olympus BF-Q190. In the next group of eight patients (Group 2), the standard bronchoscope was used for all procedures except the left upper lobe, while the left upper lobe was treated with a smaller bronchoscope, Olympus BF-P190, with an outer diameter of $4.2 \mathrm{~mm}$. In the last group of seven patients (Group 3), the smaller bronchoscope was used for every lobe. The quantum of radiofrequency treatment was measured by activations delivered to each lung lobe in each patient, and patient groups were compared by ANOVA.

Results: In this group of 27 patients, the mean age was $56.5 \pm 12.9$ years, the mean Asthma Control Questionnaire-5 item version score was $3.2 \pm 1.0$ and the mean $\mathrm{FEV}_{1} \%$ predicted was 55.2 \pm 15.7 . Bronchial thermoplasty treatment resulted in significant improvements in predicted Asthma Control Questionnaire-5 item version score (to $1.8 \pm 1.3, P<0.005$ ), salbutamol rescue usage and oral corticosteroid requiring exacerbations, with no significant change in lung function. Use of the smaller bronchoscope resulted in greater radiofrequency treatment (total activations Group 1: 155 \pm 21 , Group 2: $176 \pm 46$, Group 3: $213 \pm 37 ; P<0.01$ ). There were no significant differences in efficacy or safety outcomes among groups.

Conclusion: Using a thinner bronchoscope facilitates access to the bronchial tree and increases the radiofrequency treatment delivered at bronchial thermoplasty.

Keywords: bronchial thermoplasty, bronchoscope size, asthma

\section{Introduction}

Bronchial thermoplasty (BT) is a novel addition to the range of therapies available for the treatment of patients with severe asthma. Currently, suitable patients are characterized by having symptoms that remain poorly controlled despite high doses of inhaled corticosteroids and frequent bronchodilator use. ${ }^{1}$ It is estimated that $5 \%-10 \%$ of all asthmatics fall into this category. ${ }^{2}$

BT targets the hypertrophied airway smooth muscle, which is a characteristic feature of the asthmatic airway. ${ }^{3}$ It involves the bronchoscopic delivery of radiofrequency thermal impulses to airways ranging in size from 2 to $10 \mathrm{~mm}$, with the intention of
Correspondence: David Langton Department of Thoracic Medicine, Frankston Hospital, 2 Hastings Road, Frankston, Victoria 3199, Australia Tel +6I 397847058

Email davidlangton@phen.vic.gov.au 
reducing smooth muscle mass. ${ }^{4}$ Biopsy studies in both animals and humans have demonstrated that this is achieved successfully with BT. ${ }^{5-7}$

A standard bronchoscope used during BT, such as the Olympus BF-Q190, has a working channel of $2.0 \mathrm{~mm}$, which is sufficiently large to allow the $1.5 \mathrm{~mm}$ radiofrequency catheter to be passed easily through the instrument. The outer diameter of this bronchoscope is $4.8 \mathrm{~mm}$. This permits passage of the scope into each lobar bronchus, but generally prevents passage beyond the orifice of the segmental or fourth-generation bronchi, which have an average luminal diameter of $5.0 \pm 0.6 \mathrm{~mm} .{ }^{8}$ Recently, we have demonstrated a significant correlation between the total number of radiofrequency actuations delivered during BT and the response in the patient measured by improvement in their Asthma Control Questionnaire-5 item version (ACQ-5) score. ${ }^{9}$ That is to say, the more the actuations delivered, the greater the improvement in asthma symptom scores. It may well be the case, therefore, that using a smaller bronchoscope would allow better access to the smaller airways and, hence, a more comprehensive treatment with BT.

Olympus has recently released a smaller bronchoscope, the BF-P190, with an outer diameter of $4.2 \mathrm{~mm}$ at the distal end. In this study, we explore whether using this instrument facilitates greater radiofrequency treatment during BT when compared to using a conventionally sized bronchoscope. We hypothesize that there will be more radiofrequency actuations delivered over the same segment of lung when using the smaller scope than would be delivered using the standard scope.

\section{Patients and methods Study participants}

This was a single-center, prospective, sequential study conducted in a university teaching hospital from June 2015 to June 2018. Twenty-seven consecutive patients referred for BT agreed to participate. Each patient had been under the care of a specialist respiratory physician prior to the procedure, and each participant met the European Respiratory Society/ American Thoracic Society definition of severe asthma. ${ }^{10}$ All patients were receiving optimized asthma care including high-dose inhaled corticosteroids and two long-acting inhaled bronchodilators. The baseline data collected for all patients included age, gender, cigarette smoking history, medication usage, exacerbation frequency and ACQ-5. ${ }^{11}$

\section{Study procedures}

This study was conducted in three sequential phases. In the first group of 12 patients, the Olympus BF-Q190 broncho- scope (Olympus Medical Systems, Tokyo, Japan) was used for all procedures. BT was conducted in three treatment sessions, 4 weeks apart, first treating the right lower lobe, then the left lower lobe, and then, at the final treatment session, both upper lobes. General anesthesia was used in all cases with a laryngeal mask. The same proceduralist performed all 12 cases and these cases included all BT cases performed at our institution to that time point.

In the second group of eight participants, the lower lobe treatments were conducted in the same fashion as in the initial group. However, when the upper lobes were treated in this group, the standard scope was used only to treat the right upper lobe, whereas a smaller bronchoscope, the Olympus BF-P190, was used to treat the left upper lobe. In order to mitigate bias, two different proceduralists performed the right and left upper lobe treatments and the proceduralists were not in theater at the same time together. The display of the exact number of radiofrequency activations delivered was covered throughout the procedure and only revealed at the conclusion of the procedure.

In the third phase of this study, the smaller bronchoscope was used for all treatments. Seven patients participated in this part of the study.

\section{Outcome measures}

The primary outcome was the number of radiofrequency activations delivered when each lobe was treated. Secondary outcome measures included the response to treatment at 6 months following the completion of BT, as measured by changes in ACQ-5, rescue medication usage, exacerbation frequency and $\mathrm{FEV}_{1}$. Permission to use ACQ-5 in this study was sought and granted from the author, Elizabeth Juniper. Spirometry was conducted by experienced respiratory scientists and according to the European Respiratory Society/ American Thoracic Society standards. ${ }^{12}$ The reference predicted equations used were from the Global Lung Initiative. ${ }^{13}$

\section{Ethical considerations}

Specific approval to conduct this study was received from the Peninsula Health Human Research and Ethics Committee, and all participants provided written informed consent prior to enrollment.

\section{Statistical analysis}

One-way ANOVA was used to compare the three groups of patients in terms of 1) baseline characteristics; 2) radiofrequency activations and 3) clinical outcomes. Statistical significance was considered at $P<0.05$ for a two-tailed test. All data are presented as mean $\pm \mathrm{SD}$. 


\section{Results}

\section{Baseline characteristics}

The baseline participant details are summarized in Table 1 . This was a group of highly symptomatic, severe asthmatics with very obstructed spirometry despite using high-dose inhaled corticosteroids. There were no statistically significant differences among the three groups of patients.

\section{Radiofrequency treatment}

The quantum of radiofrequency treatment administered during each treatment session, as measured by the number of activations, is presented in Table 2 . When the standard bronchoscope was used in groups 1 and 2 in the lower lobes, the number of activations was near identical. The only difference between these two groups was related to the treatment of the left upper lobe, where a significant increase in activations was observed when the smaller bronchoscope was used.

In Group 3, where the small scope was used for all procedures, significantly more activations were observed in all lobes with the exception of the right upper lobe. Using the smaller sized bronchoscope, the mean total number of

Table I Baseline characteristics

\begin{tabular}{|l|l|l|l|l|}
\hline Characteristics & Group I & Group 2 & Group 3 & $P$-value \\
\hline Sample size, $\mathrm{n}$ & $\mathrm{I} 2$ & 8 & 7 & \\
\hline Age, years & $52.0 \pm \mathrm{I} 2.2$ & $57.8 \pm \mathrm{I} 4.4$ & $62.4 \pm 8.1$ & $\mathrm{NS}$ \\
\hline Male gender, $\mathrm{n}$ & 5 & 5 & 4 & $\mathrm{NS}$ \\
\hline BMI, kg/m & $28.8 \pm 8.2$ & $30.3 \pm 7.2$ & $27.1 \pm 4.5$ & $\mathrm{NS}$ \\
\hline $\begin{array}{l}\text { Beclomethesone, } \\
\text { mcg/day }\end{array}$ & $\mathrm{I}, 667 \pm 492$ & $\mathrm{I}, 875 \pm 640$ & $\mathrm{I}, 57 \mathrm{I} \pm 535$ & $\mathrm{NS}$ \\
\hline Salbutamol puffs/day & $7.3 \pm 8.2$ & $7.9 \pm 7.1$ & $8.3 \pm 8.4$ & $\mathrm{NS}$ \\
\hline ACQ-5 & $3.4 \pm \mathrm{I} .0$ & $3.3 \pm \mathrm{I} .4$ & $2.8 \pm 0.3$ & $\mathrm{NS}$ \\
\hline FEV $\%$ predicted & $57.1 \pm 9.3$ & $52.4 \pm \mathrm{I} 4.9$ & $54.1 \pm 25.8$ & $\mathrm{NS}$ \\
\hline $\begin{array}{l}\text { Forced expiratory } \\
\text { ratio }\end{array}$ & $56.5 \pm 7.1$ & $54.8 \pm \mathrm{I} 5.6$ & $55.0 \pm 20.4$ & $\mathrm{NS}$ \\
\hline
\end{tabular}

Notes: All data are presented as mean \pm SD unless otherwise specified. Group I: standard bronchoscope used; Group 2: mixed bronchoscopes used; Group 3: thin bronchoscope used.

Abbreviations: BMI, body mass index; ACQ-5, Asthma Control Questionnaire-5 item; NS, not significant.

Table 2 Radiofrequency activations administered by lobe

\begin{tabular}{|l|l|l|l|l|l|l|}
\hline & $\mathbf{n}$ & $\begin{array}{l}\mathbf{R} \\
\text { Lower }\end{array}$ & $\begin{array}{l}\mathbf{L} \\
\text { Lower }\end{array}$ & $\begin{array}{l}\mathbf{R} \\
\text { Upper }\end{array}$ & $\begin{array}{l}\text { L } \\
\text { Upper }\end{array}$ & Total \\
\hline $\begin{array}{l}\text { Standard scope } \\
\text { (Group I) }\end{array}$ & 12 & $42 \pm 07$ & $47 \pm 10$ & $33 \pm 05$ & $34 \pm 09$ & $155 \pm 2 I$ \\
\hline $\begin{array}{l}\text { Mixed scopes } \\
\text { (Group 2) }\end{array}$ & 8 & $4 I \pm 09$ & $47 \pm 12$ & $34 \pm 13$ & $55 \pm 2 I$ & $176 \pm 46$ \\
\hline $\begin{array}{l}\text { Small scope } \\
\text { (Group 3) }\end{array}$ & 7 & $54 \pm 14$ & $66 \pm I I$ & $34 \pm 10$ & $60 \pm 13$ & $213 \pm 37$ \\
\hline P ANOVA & & $<0.05$ & $<0.01$ & NS & $<0.01$ & $<0.01$ \\
\hline
\end{tabular}

Notes: All data are presented as mean \pm SD. Group I: standard bronchoscope used; Group 2: mixed bronchoscopes used; Group 3: thin bronchoscope used. radiofrequency activations per patient increased by $34 \%$, from $155 \pm 21$ to $213 \pm 37(P<0.01)$.

\section{Clinical outcomes}

In this group of 27 patients with severe asthma, the mean ACQ improved from $3.2 \pm 1.0$ at baseline to $1.8 \pm 1.3$ at 6 months $(P<0.005)$. Rescue salbutamol usage fell from $7.7 \pm 7.6$ puffs per day at baseline to $2.3 \pm 3.4$ puffs per day at the 6 -month mark $(P<0.01)$. Oral corticosteroid requiring exacerbations fell from $1.9 \pm 1.5$ in the 6 months pretreatment to $0.6 \pm 0.9$ in the 6 months posttreatment $(P<0.01)$. There were no significant changes in $\mathrm{FEV}_{1} \%$ predicted from baseline $(55.2 \% \pm 15.7 \%)$ to 6 months $(57.6 \% \pm 20.6 \%)$.

The three groups of patients were compared in their responses to treatment in the domains where significant changes were observed. These results are shown graphically in Figure 1. Statistically significant improvements were found after BT in each domain and in each group.

\section{Adverse events}

Of 81 procedures conducted in the 27 patients, there were five instances of readmission to hospital within 1 month of a procedure. None of these was related to the patients in Group 3. Two were related to chest infections, two to wheezing and one to gastrointestinal bleeding. All patients made a rapid and complete recovery with standard treatment.

Three patients stayed in hospital longer than the expected 24 hours. Two were discharged the following day. One patient required an Intensive Care unit stay for wheezing postprocedure, but did not require assisted ventilation, and this was the only adverse event related to Group 3 patients.

When combined, the frequency of an adverse event in Group 3 (small scope) was 1 of 21 procedures (4.8\%), whereas the risk of adverse event in Group 1 (standard scope) was 3 of 36 procedures $(8.3 \%)$. Hence, there was no signal that adverse events were more frequent using the smaller bronchoscope despite the greater number of radiofrequency activations deployed.

\section{Discussion}

This is the first study to consider the size of the bronchoscope when undertaking BT. Previous randomized control trials of BT were all undertaken with a bronchoscope $4.9-5.5 \mathrm{~mm}$ in outer diameter at the distal tip. ${ }^{14-16}$ However, since 2014, a thinner bronchoscope has been commercially available, with outer diameter $4.2 \mathrm{~mm}$ and with a working channel wide enough to allow passage of the radiofrequency catheter used in BT. The increase in total activations 
A

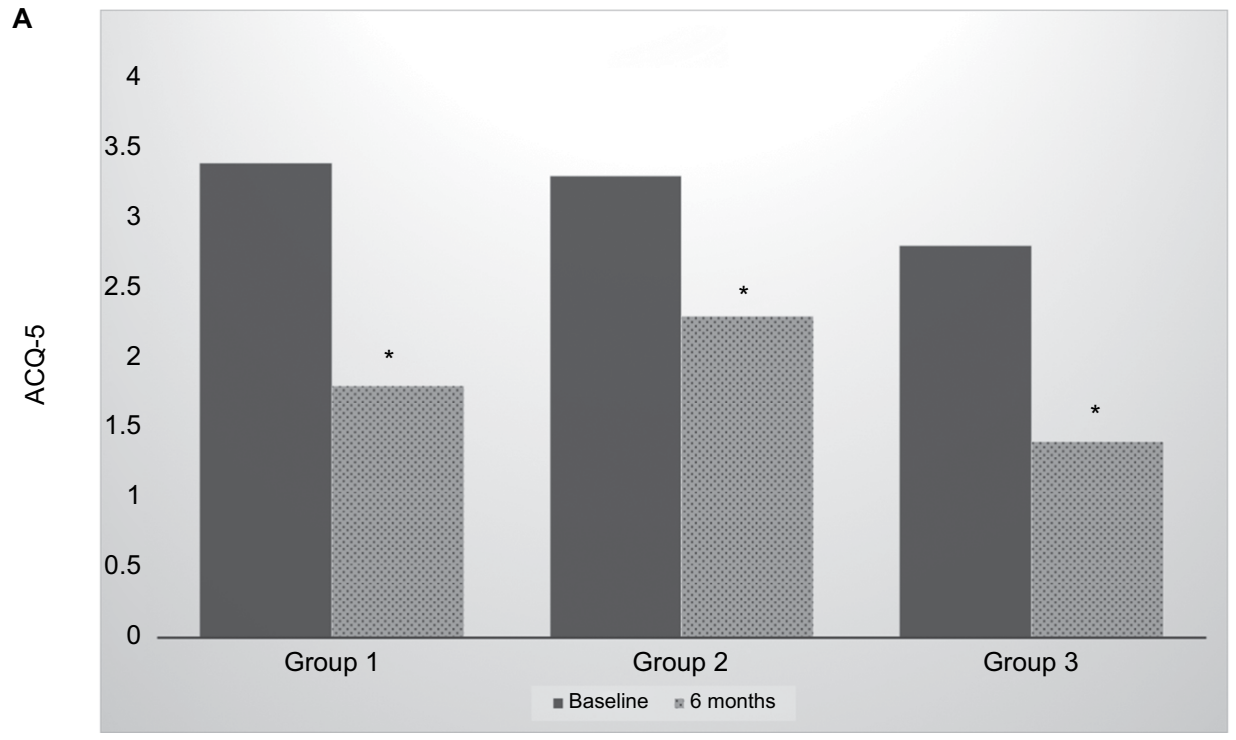

B
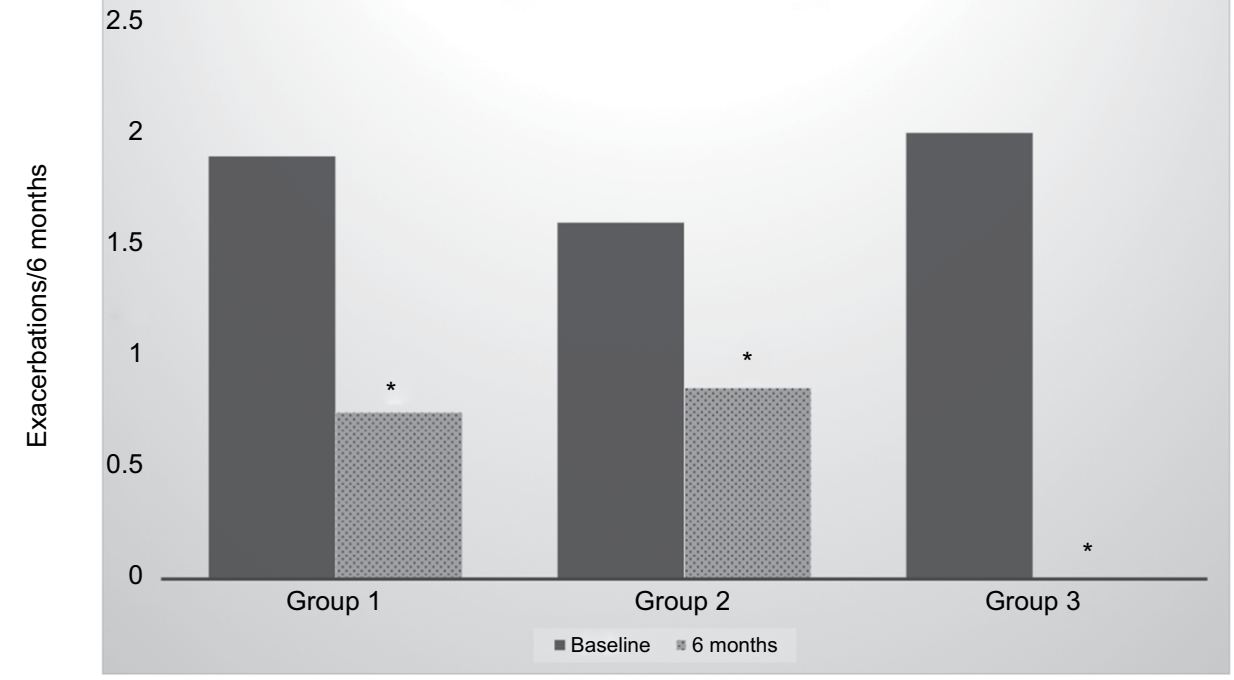

C

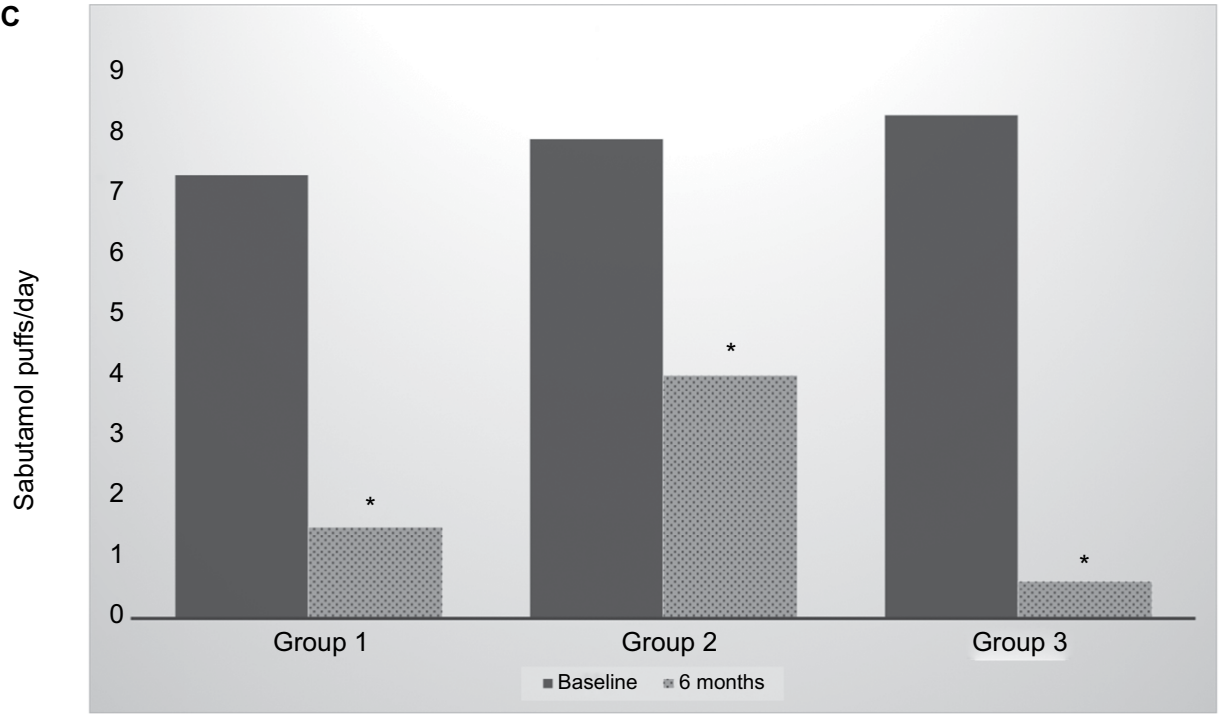

Figure I Responses to bronchial thermoplasty in each treatment group.

Notes: Group I: standard bronchoscope used; Group 2: mixed bronchoscopes used; Group 3: thin bronchoscope used.

Abbreviation: ACQ-5, Asthma Control Questionnaire-5 item. 
observed in the current study, from $155 \pm 21$ to $213 \pm 37$, or $34 \%$ when using the smaller scope, is substantive and demonstrates that the smaller scope facilitates better access to the bronchial tree and enhances the ability to undertake BT.

It is too early to say whether the improved access to the bronchial tree from using the smaller bronchoscope improves patient outcomes. The current study, being a proof-of-concept study, is not sufficiently powered to find an answer to this question. However, Figure 1 does suggest that a greater improvement may be seen in Group 3, who received the greatest radiofrequency treatment. This is consistent with our previous report that the number of radiofrequency activations delivered during BT may be a determinant of patient response to treatment. ${ }^{9}$ Ultimately, a randomized trial could be prospectively undertaken in centers with access to bronchoscopes of both sizes to compare their efficacy.

A randomized trial comparing the yield of the ultrathin bronchoscope, the Olympus BF-XP190, with the conventional bronchoscope for the sampling of peripheral pulmonary lesions has been undertaken. ${ }^{17}$ In this study, the thinner scope was demonstrated to reach more distal airways and achieve a higher sampling yield. However, whereas the ultrathin bronchoscope has an outer diameter of $3.1 \mathrm{~mm}$, which might be attractive when undertaking BT, the internal diameter of the scope is only $1.2 \mathrm{~mm}$, which is too small for the passage of the currently used radiofrequency catheter. A new bronchoscope, the Olympus-MP190F, with a $3.0 \mathrm{~mm}$ distal end and a larger internal channel of $1.7 \mathrm{~mm}$ is now in commercial production, but this bronchoscope has a metallic distal tip and cannot be used with electrical procedures. ${ }^{18}$

In using a thinner bronchoscope, there may also be some disadvantages that need consideration. For example, the increase in activations potentially could prolong the performance of each BT procedure. That said, in our experience, we have not found that to be a significant practical issue. Additionally, there is evidence that the number of activations per procedure is one factor in the immediate fall in $\mathrm{FEV}_{1}$ in the 24 hours postprocedure. ${ }^{19}$ Therefore, there potentially exists a tradeoff between increasing the effectiveness by increasing activations while avoiding undue wheeziness postprocedure. In the current study, however, there was no evidence that adverse events were any more frequent when using the smaller scope.

\section{Conclusion}

Using a thinner bronchoscope increases the ease of delivery of BT by facilitating access to the bronchial tree. This is wor- thy of further evaluation to establish whether this improves clinical outcomes.

\section{Data sharing statement}

Original data can be sourced by contacting the corresponding author.

\section{Author contributions}

All authors contributed toward data analysis, drafting and revising the paper and agree to be accountable for all aspects of the work.

\section{Disclosure}

DL was the recipient of a postgraduate scholarship from Monash University. The authors report no other conflicts of interest in this work.

\section{References}

1. Global Initiative for Asthma. Global strategy for asthma management and prevention, 2017. Available from: www.ginasthma.org.

2. von Bülow A, Kriegbaum M, Backer V, Porsbjerg C. The prevalence of severe asthma and low asthma control among Danish adults. J Allergy Clin Immunol Pract. 2014;2(6):759-767.

3. James AL, Bai TR, Mauad T, et al. Airway smooth muscle thickness in asthma is related to severity but not duration of asthma. Eur Respir J. 2009;34(5):1040-1045.

4. Laxmanan B, Hogarth DK. Bronchial thermoplasty in asthma: current perspectives. J Asthma Allergy. 2015;8:39-49.

5. Danek CJ, Lombard CM, Dungworth DL, et al. Reduction in airway hyperresponsiveness to methacholine by the application of RF energy in dogs. J Appl Physiol. 2004;97(5):1946-1953.

6. Pretolani M, Dombret MC, Thabut G, et al. Reduction of airway smooth muscle mass by bronchial thermoplasty in patients with severe asthma. Am J Respir Crit Care Med. 2014;190(12):1452-1454.

7. Chakir J, Haj-Salem I, Gras D, et al. Effects of bronchial thermoplasty on airway smooth muscle and collagen deposition in asthma. Ann Am Thorac Soc. 2015;12(11):150901124524008-1618.

8. Montaudon M, Desbarats P, Berger P, de Dietrich G, Marthan R, Laurent F. Assessment of bronchial wall thickness and lumen diameter in human adults using multi-detector computed tomography: comparison with theoretical models. J Anat. 2007;211(5):579-588.

9. Langton D, Sha J, Ing A, Fielding D, Thien F, Plummer V. Bronchial thermoplasty: activations predict response. Respir Res. 2017;18(1):134.

10. Chung KF, Wenzel SE, Brozek JL, et al. International ERS/ATS guidelines on definition, evaluation and treatment of severe asthma. Eur Respir J. 2014;43(2):343-373.

11. Juniper EF, Svensson K, Mörk AC, Ståhl E. Measurement properties and interpretation of three shortened versions of the asthma control questionnaire. Respir Med. 2005;99(5):553-558.

12. Miller MR, Crapo R, Hankinson J, et al. General considerations for lung function testing. Eur Respir J. 2005;26(1):153-161.

13. Quanjer PH, Stanojevic S, Cole TJ, et al. Multi-ethnic reference values for spirometry for the 3-95-yr age range: the global lung function 2012 equations. Eur Respir J. 2012;40(6):1324-1343.

14. Castro M, Rubin AS, Laviolette M, et al. Effectiveness and safety of bronchial thermoplasty in the treatment of severe asthma: a multicenter, randomized, double-blind, sham-controlled clinical trial. Am J Respir Crit Care Med. 2010;181(2):116-124. 
15. Cox G, Thomson NC, Rubin AS, et al. Asthma control during the year after bronchial thermoplasty. N Engl J Med. 2007;356(13):1327-1337.

16. Pavord ID, Cox G, Thomson NC, et al. Safety and efficacy of bronchial thermoplasty in symptomatic, severe asthma. Am J Respir Crit Care Med. 2007;176(12):1185-1191.

17. Oki M, Saka H, Ando M, et al. Ultrathin bronchoscopy with multimodal devices for peripheral pulmonary lesions. A randomized trial. Am J Respir Crit Care Med. 2015;192(4):468-476.
18. Oki M, Saka H, Kitagawa C, et al. Novel thin bronchoscope with a 1.7-mm working channel for peripheral pulmonary lesions. Eur Respir J. 2008;32(2):465-471.

19. Langton D, Wang W, Thien F, Plummer V. The acute effects of bronchial thermoplasty on $\mathrm{FEV}_{1}$. Respir Med. 2018;137:147-151.

\section{Publish your work in this journal}

The Journal of Asthma and Allergy is an international, peer-reviewed open access journal publishing original research, reports, editorials and commentaries on the following topics: Asthma; Pulmonary physiology; Asthma related clinical health; Clinical immunology and the immunological basis of disease; Pharmacological interventions and new therapies. This journal is included in PubMed. The manuscript management system is completely online and includes a very quick and fair peer-review system, which is all easy to use. Visit http://www dovepress.com/testimonials.php to read real quotes from published authors. 